\title{
White Carrot
}

National Cancer Institute

\section{Source}

National Cancer Institute. White Carrot. NCI Thesaurus. Code C126649.

A vegetable, also known as Arracacha, with potential chemoprevenitve, anti-oxidant and protective activities. White carrot contains a variety of nutrients, including minerals and vitamins. Polyacetylenes, including falcarinol, falcarindiol and falcarindiol-3-acetate are mainly responsible for its potential anti-cancer activity. 